\title{
Clinical manifestations of dengue hemorrhagic fever in Puerto Rico, 1990-19911
}

\author{
José G. Rigau-Pérez ${ }^{2}$ and \\ the Puerto Rico Association of Epidemiologists ${ }^{3}$
}

\begin{abstract}
The aim of the study reported here was to demonstrate that dengue hemorrhagic fever occurs in Puerto Rico, that it is underreported, and that this underreporting is due partly to underdiagnosis in hospitals. Surveillance for severe dengue identified 986 hospitalizations for suspected dengue in 1990-1991. At the time, on the basis of available clinical and laboratory data, the surveillance system routinely identified 20 DHF cases, including three with dengue shock syndrome (DSS). Our subsequent review of these 986 patients' hospital records identified 102 whose records supported a clinical diagnosis of DHF (88) or DSS (14). Of the 102, there were 57 with positive virologic or serologic results for dengue and that met the World Health Organization criteria for DHF (fever, hemorrhagic manifestations, thrombocytopenia, and excessive capillary permeability). This group of 57 patients had a mean age of 38 years, contained a preponderance of males $(34,59.3 \%)$, included eight cases of DSS, and involved two $(3.5 \%) \mathrm{fa}$ talities (in females 16 and 55 years old). Hemorrhagic manifestations were mild; hemoconcentration, hypoalbuminemia, and elevated aspartate and alanine aminotransferase (AST and $A L T$ ) levels were frequently encountered. The median duration of hospitalization was five days. The clinical description of these laboratory-positive DHF cases in Puerto Rico is consistent with previous descriptions of DHF in the medical literature; but the patients' age distribution is similar to the pattern typically found in the Americas (where all age groups tend to be affected), as opposed to Southeast Asia (where mostly younger children are affected). The number of DHF cases identified by our study was nearly three times that reported through the established surveillance system. Our findings indicate that recognition and reporting of DHF by local clinicians needs to be improved.
\end{abstract}

Dengue is an acute mosquito-transmitted disease caused by any of four

\footnotetext{
1 A Spanish version of this article will also be published in this journal.

2 Dengue Branch, National Center for Infectious Diseases, Division of Vector-Borne Infectious Diseases, Centers for Disease Control and Prevention, San Juan, Puerto Rico. Mailing address: San Juan Laboratories, CDC, 2 Calle Casia, San Juan, Puerto Rico 00921-3200.

3 The Puerto Rico Association of Epidemiologists is a multidisciplinary, voluntary organization of professionals dedicated to the practice of epidemiology and infection control in Puerto Rico.
}

virus serotypes (DEN-1, DEN-2, DEN3 , or DEN-4) that is characterized by a sudden onset of fever, headache, myalgia, and rash. The disease is endemic, with increasing incidence in most tropical areas, and constitutes one of the world's emerging microbial disease threats $(1,2)$. Large outbreaks of dengue and dengue hemorrhagic fever (DHF) have occurred recently in South and Central America and the Caribbean islands. Only one mosquito vector, Aedes aegypti, has been impli- cated in dengue transmission in these areas.

Dengue fever (DF) is usually selflimited and not life-threatening. The potentially life-threatening DHF is most commonly reported in Southeast Asia, where over a million cases were reported from 1986 to 1990, and where DHF has become a frequent cause of hospitalization and death in children (3). The feature distinguishing DHF from DF is not the occurrence of hemorrhage, but rather the occurrence of 
plasma leakage due to increased capillary permeability_which may lead insidiously and rapidly to dengue shock syndrome (DSS) with hypotension or frank shock (4-7). Although dengue shock is usually reversible with aggressive fluid therapy, prevention of shock is the key to successful therapy. After shock develops, the case fatality rate, even in experienced centers, may be over $10 \%$ (7-10). There are, in addition, severe and fatal cases that do not present with plasma leakage but with early, severe gastrointestinal hemorrhage (11).

The first case of DHF in the Americas was confirmed in Puerto Rico in 1975 (12). Despite active surveillance, occurrence of a DHF epidemic in Cuba in 1981, and DHF outbreaks in Mexico (1984) and Nicaragua (1985), only three cases of DHF were documented in Puerto Rico up to the end of 1985 (13-15). However, an island-wide epidemic the following year caused 29 DHF cases (including three deaths) whose association with dengue infection was determined by serologic or virologic methods $(15,16)$. Since then, and until 1994, while DHF outbreaks were reported in Central and South America, only a small number of DHF cases were recognized annually in Puerto Rico $(17,18)$.

The study reported here was undertaken to demonstrate that DHF, as defined by World Health Organization (WHO) criteria (19) and described in Southeast Asia, occurs in Puerto Rico; that it is underreported; and that this underreporting is due partly to underdiagnosis in hospitals. The implications of these findings for hospitalbased diagnosis and treatment of DHF are discussed.

\section{METHODS}

\section{Clinical case definitions}

WHO has four criteria for reporting DHF: "(1) fever; (2) hemorrhagic manifestations including at least a positive tourniquet test (except in shock cases), and perhaps minor or major bleeding phenomena; (3) thrombocytopenia (100 $000 / \mathrm{mm}^{3}$ or less); (4) hemoconcentration: hematocrit increased by $20 \%$ or more, or objective evidence of capillary permeability" (19). Because a positive tourniquet test is a mild, provoked hemorrhagic phenomenon, for this study the second criterion was interpreted as meaning any hemorrhagic manifestation, including minor bleeding phenomena as mild as a positive tourniquet test. Following WHO guidelines, hypoalbuminemia and/or pleural or abdominal effusions (documented by X-ray, ultrasound, or CT-scan) were considered objective evidence of the capillary permeability cited in the fourth criterion.

Dengue shock syndrome (DSS) was defined in terms of the above criteria plus hypotension or narrow pulse pressure $(\leq 20 \mathrm{~mm} \mathrm{Hg})$. The following WHO grades for DHF severity (19) were used: (I) a positive tourniquet test is the only hemorrhagic manifestation; (II) spontaneous bleeding; (III) evidence of circulatory failure (narrowing of pulse pressure or hypotension); (IV) profound shock with undetectable blood pressure and pulse. Cases of Grade III and Grade IV DHF are cases of DSS.

\section{Screening for possible DHF cases}

The Dengue Branch of the U.S. Centers for Disease Control and Prevention $(C D C)$ receives blood specimens from patients with suspected dengue or DHF cases that are provided by public and private facilities throughout Puerto Rico $(20,21)$. Basic demographic and clinical information, as well as a record of diagnostic laboratory test results, are maintained in a computer database.

A parallel surveillance system, separate from the one collecting diagnostic serum samples, is made possible by reports from hospital infection control nurses (ICNs) organized as the Puerto Rico Association of Epidemiologists. They provide clinical information about inpatients with possible or actual cases of DF. The reporting form used by ICNs includes about 40 data items on the patient's signs, symptoms, and laboratory findings relating to DHF.

In 1991, reports from Puerto Rico's Forensic Medicine Institute and Demographic Registry were also included in the compilation.

A computer screening algorithm was applied to the 1990 and 1991 reports from all four sources (CDC, ICNs, Forensic Medicine Institute, and Demographic Registry) to identify fatalities, patients who fulfilled WHO DHF and DSS criteria, and patients who only met three of the four WHO criteria. For this stage of screening, hypoalbuminemia was defined as a serum albumin level of less than $3 \mathrm{~g} / \mathrm{dL}$. The cases identified by the algorithm were selected for hospital record review conducted by one of the authors (JGRP).

\section{Hospital record review}

To identify abnormal test results in a patient's hospital record, we used each hospital's standards for serum albumin, protein, aspartate aminotransferase (AST, previously called serum glutamic oxaloacetic transaminase or SGOT), alanine aminotransferase (ALT, previously called serum glutamic pyruvic transaminase or SGPT), prothrombin time, and partial thromboplastin time. The normal value used for total bilirubin was $\leq 1 \mathrm{mg} / \mathrm{dL}$ $(22,23)$. Fever may cause the number of erythrocytes seen in the urine sediment to increase; therefore, microhematuria was defined by the presence of more than five red blood cells per high-power field or a positive result for blood in the urinalysis (24). Data abstraction focused on the criteria for diagnosis of DHF, without attempting to describe all clinical findings. Cases were grouped according to the month of onset of symptoms. Because of the small sizes of the groups and the nonrandomness of samples, tests of significance to demonstrate differences among groups were not performed. 


\section{Laboratory methods}

In connection with diagnostic efforts around the time of illness, serum samples collected less than six days after the onset of illness were processed for virus isolation in C6/36 mosquito cell cultures or were inoculated into Toxorhynchites mosquitoes (25-27). Dengue viruses were identified by using serotype-specific monoclonal antibodies in an indirect fluorescent antibody test of either virus-infected cell cultures or tissues from inoculated mosquitoes. Serum specimens were tested for anti-dengue IgM by the IgM antibody capture ELISA method (MAC-ELISA) (28-30). Specimens from which dengue virus was isolated were further evaluated by either hemagglutination-inhibition (HI) testing or IgG-ELISA to determine whether the infection was primary or secondary, a determination based on anti-dengue antibody levels in acutephase or convalescent-phase serum specimens. In addition, specimens with borderline results by MACELISA were tested by HI or IgG-ELISA in an attempt to confirm the diagnosis by detecting an anamnestic antidengue antibody response (30-32).

\section{Laboratory case definitions}

Confirmation of a current dengue infection was based on the following criteria: (1) dengue virus isolation from serum or autopsy tissue samples; or (2) seroconversion from negative to positive, or a four-fold or greater change in the anti-dengue antibody titers of paired serum specimens. Demonstration of dengue virus antigen in autopsy tissue samples by immunofluorescence or immunocytochemical analysis was attempted (33) but proved negative in all instances.

A current primary case was defined as (1) an IgM-positive (optical density $>0.20)$ case with an acute-phase $(\leq 5$ days after disease onset) serum sample with no anti-dengue antibody by $\mathrm{HI}$ (titer $<10)$ but with a convalescentphase ( $\geq 14$ days after onset) serum sample with an anti-dengue antibody HI titer <2 560; or (2) a case in which virus was isolated from a single acutephase serum sample with no antidengue antibody detectable by HI.

A current secondary case was defined as (1) a case with an IgM-positive acute-phase serum sample containing detectable antibody by $\mathrm{HI}$ and a convalescent-phase serum sample with an $\mathrm{HI}$ antibody titer $\geq 2560$; or (2) a case in which virus was isolated from a single acute-phase serum sample containing anti-dengue antibody detectable by $\mathrm{HI}(34,35)$.

Probable dengue cases were defined as those in individuals (1) who had a stable anti-dengue HI antibody level in paired serum samples combined with IgM positivity in either sample; or (2) who submitted a single serum sample that was IgM positive or that had an HI antibody titer $\geq 1280$ or an IgG antibody titer by ELISA $\geq 163840$. These cases were only considered probable because the individuals involved might have had dengue within the past three months (IgM may be present for 90 days or longer), and the symptoms at the time of blood collection might have been due to an illness other than dengue $(28,29)$.

Unless otherwise stated, probable and confirmed cases were considered together as laboratory-diagnosed or laboratory-positive cases. Single specimens negative for virus and for IgM, if collected less than six days after the onset of illness, were considered nondiagnostic, and the case was classified as indeterminate. For specimens collected six or more days after the onset of symptoms, an absence of IgM was deemed to rule out a dengue diagnosis, and the case was considered negative.

\section{RESULTS}

In 1990 and 1991, the ICNs, the Forensic Medicine Institute, and the Demographic Registry provided 986 reports of hospitalizations for suspected dengue in Puerto Rico. (This was only $5.7 \%$ of the 17328 dengue cases reported to the CDC for those two years.) On the basis of the signs and symptoms noted in the 986 reports of hospitalizations or deaths and the results obtained with diagnostic samples submitted to the laboratory-based surveillance system, 17 DHF and three DHF/DSS cases with a positive laboratory diagnosis of dengue were identified. These 20 cases were those that the system was able to routinely detect, and they therefore constituted the number of reported DHF cases.

The screening of the remaining 966 reports to identify possible DHF cases produced 199 candidate cases of DHF; two reports based on outpatient visits were eliminated from further study. Subsequently, the hospital records of all 20 DHF cases and 197 candidate DHF cases were reviewed. The 217 hospitalization records supported a clinical diagnosis of DHF in 88 cases, and of DHF/DSS in 14 cases. The records of the 115 remaining cases were found to be compatible with a clinical diagnosis of DF, but many of these cases could not be further classified for lack of information on the following symptoms or tests: fever (2), tourniquet test (103), blood in stool (97), urinalysis for blood (4), repeat hematocrit (5), and serum albumin (20). It should be noted that this group included two of the 20 originally reported DHF cases, which did not have sufficient evidence on record to fulfill the four diagnostic criteria for DHF (one case did not report fever, and the other did not report bleeding). The case-fatality rate of the 115 patients was $5.2 \%$, there being six deaths.

Fifty-three $(46.1 \%)$ of the $115 \mathrm{DF}$ cases were laboratory-positive. Of those, $15(28.3 \%)$ had a discharge diagnosis of DHF, although 11 of them did not have any evidence on record of excessive capillary permeability. In contrast, dengue was not mentioned among the diagnoses at death for any of the three patients (5.7\%) dying among the laboratory-positive DF subgroup. Those dying included a 61year-old man with a diagnosis of perforated pyloric ulcer, peritonitis, and hepatic coma; a 35-year-old woman with a diagnosis of acute myelomono- 
cytic leukemia and chemical hepatitis together with a diagnosis of intracerebral hemorrhage and chronic active hepatitis; and a 48-year-old woman with a diagnosis of hepatic failure. No details were available on the history of hepatic disease in these fatal cases.

The 102 cases identified by our record review as clinically compatible with DHF or DSS included 57 positive by serologic or virologic methods, 29 with indeterminate laboratory results, and 16 with negative laboratory results. Of the 57 positives, 42 yielded results indicating they were probable cases; 11 were confirmed by serologic methods; and four were confirmed and yielded the following dengue viruses: one case yielded DEN-1, two yielded DEN-2 (group II genotype), and one yielded DEN-4 (36).

Of the 15 confirmed cases, one could be classified as involving a primary immune response, while the other 14 involved secondary infections. Of the 16 with negative results, only two had a clear diagnosis of other conditions (acute suppurative appendicitis in one case, leukemia in the other). Table 1 shows the characteristics of the cases that fulfilled the clinical criteria for DHF, grouped according to whether the dengue laboratory diagnosis was positive, indeterminate, or negative.

The positive and indeterminate groups were similar; but the patients with negative dengue laboratory results were dissimilar, having an equal sex ratio, a considerably lower mean age than the other two groups, and no fatalities. The median month of onset of symptoms for indeterminates and negatives was August, at the usual start of the yearly increase in dengue incidence; while the corresponding month for positives was October, at or near the annual peak dengue incidence. The mean length of the patients' hospital stay was longest (8.9 days) for the negatives.

A profile of the progression of the illness (Table 2) was developed by calculating the mean time from onset of symptoms to hospital admission, highest hematocrit, lowest hematocrit, lowest platelet count, lowest diastolic
TABLE 1. Characteristics of 102 suspected dengue cases (out of 986 reviewed) whose hospitalization records supported a clinical diagnosis of DHF, grouped according to whether the laboratory diagnosis was dengue-positive, indeterminate, or negative. Puerto Rico, 1990-1991

\begin{tabular}{|c|c|c|c|}
\hline \multirow[b]{2}{*}{ Variable } & \multicolumn{3}{|c|}{ Dengue laboratory diagnosis } \\
\hline & Positive $(n=57)$ & Indeterminate $(n=29)$ & Negative $(n=16)$ \\
\hline Sex ratio (m:f) & $1.5: 1$ & $2.2: 1$ & $1: 1$ \\
\hline $\begin{array}{l}\text { Age } \\
\text { Mean } \\
\text { Range }\end{array}$ & $\begin{array}{l}38 \text { years } \\
4-86 \text { years }\end{array}$ & $\begin{array}{c}35 \text { years } \\
7 \text { months }-91 \text { years }\end{array}$ & $\begin{array}{l}27 \text { years } \\
10-73 \text { years }\end{array}$ \\
\hline Deaths & $\begin{array}{l}2(3.5 \% \text {; females } 16 \\
\text { and } 55 \text { years old })\end{array}$ & $\begin{array}{l}3(10.3 \% ; 2 \text { males } 34 \\
\text { and } 39 \text { years old; } \\
1 \text { female } 85 \text { years old })\end{array}$ & \\
\hline $\begin{array}{l}\text { Month of onset of symptoms } \\
\text { (median) }\end{array}$ & October & August & August \\
\hline Towns of residence ${ }^{a}$ & 24 & 17 & 14 \\
\hline Hospitals providing care ${ }^{\mathrm{a}}$ & 20 & 15 & 7 \\
\hline $\begin{array}{l}\text { Patients receiving private } \\
\text { hospital care }\end{array}$ & $39(68.4 \%)$ & $15(51.7 \%)$ & $11(68.8 \%)$ \\
\hline $\begin{array}{l}\text { Length of hospital stay, in days } \\
\text { Median } \\
\text { Range } \\
\text { Mean }\end{array}$ & $\begin{array}{c}5 \\
2-42 \\
6.8\end{array}$ & $\begin{array}{c}5 \\
0-19 \\
6.0\end{array}$ & $\begin{array}{c}5 \\
2-39 \\
8.9\end{array}$ \\
\hline
\end{tabular}

a Puerto Rico has 78 municipalities and 65 reporting hospitals. blood pressure, and hospital discharge. In the positives, the highest hematocrit (signaling hemoconcentration) was detected an average of one day before the platelet count and diastolic blood pressure reached minimal levels. This was also the pattern in the indeterminates. In the negatives, how- ever, the highest hematocrit was found to occur an average of one day after the lowest platelet count and diastolic pressure.

Most of the 57 DHF patients identified by hospital record review who had positive laboratory results (see Table 1) had dengue listed on their
TABLE 2. Profile of the progression of illness of the 102 cases whose hospitalization records supported a clinical diagnosis of DHF, by laboratory diagnosis. Puerto Rico, 1990-1991

\begin{tabular}{lccc}
\hline \multicolumn{1}{c}{ Variable } & \multicolumn{3}{c}{ Dengue laboratory diagnosis } \\
\cline { 2 - 4 } & Positive $(n=57)$ & Indeterminate $(n=29)$ & Negative $(n=16)$ \\
\hline $\begin{array}{l}\text { Mean days } \\
\text { from onset of }\end{array}$ & & \\
symptoms to: & 4.7 & 3.8 & \\
Admission & 5.8 & 4.2 & 5.6 \\
Highest hematocrit & 7.5 & 7.0 & 7.4 \\
Lowest hematocrit & 6.6 & 5.4 & 10.1 \\
Lowest platelet count & 6.6 & 5.4 & 6.1 \\
Lowest diastolic blood pressure & 11.4 & 9.6 & 6.5 \\
Discharge & & & 14.6 \\
\hline
\end{tabular}


records as the diagnosis for hospital admission $(35,61.4 \%)$ or discharge $(45,78.9 \%)$; the rest were admitted or discharged with diagnoses such as thrombocytopenia, bleeding, or viral syndrome. Six of the 57 patients $(10.5 \%)$ had a diagnosis of DHF at admission, but only four of those still carried it at discharge. An additional 19 had DHF as a discharge diagnosis, so that a total of $23(40.4 \%)$ of the $57 \mathrm{DHF}$ cases with a positive laboratory diagnosis of dengue had the correct diagnosis at discharge. Seventeen $(29.8 \%)$ of the patients came from a single hospital located in the San Juan metropolitan area; no other hospital reported more than six $(10.5 \%)$ of the 57 cases.

Tables 3 and 4 show the frequency of signs and symptoms and selected clinical laboratory results for the 57 laboratory-positive dengue patients with DHF or DSS. As required by the WHO case definition, all had fever, hemor-

TABLE 3. Signs and symptoms of the 57 hospitalized laboratory-positive patients with DHF (Puerto Rico, 1990-1991)

\begin{tabular}{lrr}
\hline & \multicolumn{2}{c}{ Patient $^{\mathrm{a}}$} \\
\cline { 2 - 3 } \multicolumn{1}{c}{ Symptom or sign } & No. & $(\%)$ \\
\hline Fever & 57 & $(100.0)$ \\
Rash & 27 & $(47.4)$ \\
Hepatomegaly & 6 & $(10.5)$ \\
Effusions & 3 & $(5.3)$ \\
Frank shock & 3 & $(5.3)$ \\
Any hemorrhage & 57 & $(100.0)^{\mathrm{b}}$ \\
Microscopic hematuria & 28 & $(51.9)^{\mathrm{c}}$ \\
Petechiae & 26 & $(45.6)$ \\
Epistaxis & 13 & $(22.8)$ \\
Gingival hemorrhage & 8 & $(14.0)$ \\
Blood in stools & 8 & $(14.0)$ \\
Positive tourniquet test & 5 & $(31.3)^{\mathrm{d}}$ \\
Blood in vomitus & 4 & $(7.0)$ \\
Bleeding at injection or & \multicolumn{3}{c}{} \\
$\quad$ venipuncture site & 4 & $(7.0)$ \\
Hemoptysis & 3 & $(5.3)$ \\
Vaginal hemorrhage & 2 & $(3.5)$ \\
Gross hematuria & 2 & $(3.5)$ \\
Other hemorrhage & 2 & $(3.5)$ \\
\hline a The numbers given are minimum estimates, because the \\
search was not uniform for all patients; however, the de- \\
nominator was equal to 57 except where noted. \\
b Only two (3.5\%) of the 57 patients had severe hemorrhagic \\
manifestations. \\
c Denominator = 54. \\
d Denominator = 16. & \multicolumn{3}{|}{} \\
\end{tabular}

TABLE 4. Clinical laboratory analyses recorded for the 57 hospitalized laboratory-positive patients with DHF (Puerto Rico, 1990-1991). Abbreviations: AST = aspartate aminotransferase, previously called serum glutamic oxaloacetic transaminase (SGOT); ALT = alanine aminotransferase, previously called serum glutamic pyruvic transaminase (SGPT); PT = prothrombin time; PTT = partial thromboplastin time

\begin{tabular}{|c|c|c|c|c|}
\hline \multirow[b]{2}{*}{ Tests with abnormal results } & \multicolumn{2}{|c|}{ Patients } & \multicolumn{2}{|c|}{ Results } \\
\hline & $\begin{array}{l}\text { No. pos./ } \\
\text { No. tested }\end{array}$ & (\% positive) & $\begin{array}{l}\text { Average } \\
\text { result }\end{array}$ & (Range) \\
\hline \multicolumn{5}{|l|}{ Thrombocytopenia } \\
\hline Platelet count $\leq 100000 / \mathrm{mm}^{3}$ & $57 / 57$ & $(100.0)$ & 45980 & $(9-99000)$ \\
\hline \multicolumn{5}{|l|}{ Increased capillary permeability } \\
\hline Hemoconcentration $\geq 0.20$ & $34 / 57$ & $(59.6)$ & 0.26 & $(0-1.0)$ \\
\hline Low serum protein & $18 / 51$ & (35.3) & 6.3 & (3.8-8.3) \\
\hline Low serum albumin & $35 / 52$ & (67.3) & 3.5 & $(2.3-4.9)$ \\
\hline \multicolumn{5}{|l|}{ Liver involvement } \\
\hline Elevated AST (SGOT) & $42 / 50$ & (84.0) & 260 & $(19-13368)$ \\
\hline Elevated ALT (SGPT) & $34 / 48$ & (70.8) & 242 & $(118-2607)$ \\
\hline Total bilirubin $>1 \mathrm{mg} / \mathrm{dL}$ & $5 / 45$ & $(11.1)$ & 1.2 & $(0.1-21.2)$ \\
\hline \multicolumn{5}{|l|}{ Bleeding tendencies } \\
\hline PT $>25 \%$ over control & $2 / 43$ & $(4.7)$ & $13 \%$ over control & $(-10-390 \%)$ \\
\hline PPT $>25 \%$ over control & $18 / 43$ & (41.9) & $33 \%$ over control & $(0-249 \%)$ \\
\hline
\end{tabular}

average result for the tested cases.

rhagic manifestations, thrombocytopenia, and some evidence of abnormal capillary permeability (effusions, low albumin, or hemoconcentration). The most frequent hemorrhagic manifestations were microscopic hematuria and petechiae; only two patients (3.5\%) suffered serious or severe hemorrhages. While AST and ALT levels were frequently only mildly elevated, they respectively surpassed $500 \mathrm{U} / \mathrm{L}$ in five $(10.0 \%)$ and seven $(14.6 \%)$ of the cases in which they were measured. Derangements in partial thromboplastin time results were more frequent and more pronounced than derangements in prothrombin time results. The ratio of AST to ALT levels ranged from 0.08 to 3.96 , and in $40(85.1 \%)$ of 47 patients tested the ratio was under 2.00. (A similar pattern was observed among the laboratory-negative and indeterminate clinically diagnosed DHF cases.)

There were no patients for whom a positive tourniquet test was the only hemorrhagic manifestation (DHF grade I), but there were 49 cases of grade II DHF, five of grade III (DSS), and three of grade IV (including two fatalities). One fatal case (age 16, a confirmed DHF case with secondary dengue infection) was admitted in a coma with tonic-clonic seizures. She developed hypotension within 24 hours of admission and died in cardiorespiratory arrest after 10 days of hospitalization. The other fatality (age 55, a confirmed DHF case with DEN-2 infection and secondary response) presented with fever and thrombocytopenia $\left(27000 / \mathrm{mm}^{3}\right)$, developed hypotension within 24 hours of admission, and died in cardiorespiratory arrest after three days of hospitalization. In this latter case, the principal diagnoses noted at death were hepatic failure and pancreatitis; dengue was not included.

Other infectious diseases considered for alternative testing in these 57 cases were mononucleosis (14 cases, $24.6 \%$ ), hepatitis (A, B, or C; four cases, $7.0 \%$ ), and cytomegalovirus infection (three cases, $5.3 \%$ ). None of these alternative tests yielded positive results. Other diagnostic studies performed on these patients included bone marrow aspiration (five patients, 8.8\%), CT scanning (four patients, $7.0 \%$ ), and ultrasound (four patients, $7.0 \%$ ). Therapy included intravenous fluid replacement for all DHF cases, and frequently also included steroids (in 16 cases, 28.1\%) 
and platelet transfusions (in 13 cases, $22.8 \%)$. Two cases $(3.5 \%)$ received intravenous immune globulin, and two $(3.5 \%)$ received fresh frozen plasma.

\section{DISCUSSION}

This investigation provides the first description of the clinical characteristics of endemic DHF cases in Puerto Rico. These cases were identified by reviewing the hospital records of cases reported through the island's parallel laboratory-based and hospital-based dengue surveillance systems. The observed incidence of DHF with a positive laboratory diagnosis of dengue was nearly three times greater than the incidence detected by the surveillance system (57 cases vs. 20), and even the larger figure appears to have been only a fraction of all the DHF cases that occurred. Among the laboratory-positive cases of DHF, $59.6 \%$ were discharged without a diagnosis of DHF; and one death was attributed not to dengue but to hepatic failure and pancreatitis. In addition, 29 cases of possible DHF did not submit appropriate samples for dengue diagnosis. All this strongly indicates that recognition of DHF among clinicians needs to be improved.

Of the 115 patients whose clinical records were compatible with a DF diagnosis, 53 were laboratory-positive for dengue. Of these 53, there were 15 (28.3\%) that had a discharge diagnosis of DHF; but the records of 11 showed no evidence of excessive capillary permeability. This suggests that capillary permeability is not commonly considered a criterion for DHF diagnosis. Also, six deaths occurred among these 115 patients, with three of them occurring among the 53 laboratory-positive patients. Such a high case-fatality rate (3/53 or $5.7 \%$ ) among DF patients suggests that the group included DHF cases that did not fulfill the case definition for lack of complete information, or else (as reported in other locations) that dengue infections with fatal outcomes at times develop without capillary leakage (11). In either case prompt, accurate diagnosis of DHF cases is necessary, not just for surveil- lance purposes but for prevention of shock and ensuing death.

The clinical features of laboratorypositive DHF cases in Puerto Rico and the profile of DHF's progression (see Table 2) are similar to those of cases reported in countries with severe epidemics or long-established DHF endemicity. Other descriptions indicate that thrombocytopenia is a harbinger of capillary leakage, hemoconcentration, and hypotension; our data (which show the time intervals to extreme values, not to the first abnormal value) are consistent with this point (37-42).

In contrast to other reports, however, microscopic hematuria was the most frequently detected hemorrhagic manifestation (in $51.9 \%$ of the 57 DHF cases), while the tourniquet test was positive in only five (31.3\%) of 16 patients tested. Both findings reflect clinical practices in Puerto Rico, where chemical and automated microscopic tests for hematuria are widely available, and where the tourniquet test is used infrequently. Hematuria was also prominent in the 1971 Tahiti epidemic and among the 29 DHF cases reported in Puerto Rico's 1986-1987 epidemic $(43,44)$.

Hepatomegaly has been reported as a common finding among children with DHF in Indonesia, India, and Thailand (64.9-90.0\%); but it was noted in only six $(10.5 \%)$ of the 57 DHF cases reported here $(37,45,46)$. As in our study, however, hepatomegaly was seen in only a minority of the DHF cases studied in Indonesia in 1976, Cuba in 1981, Manila in 1983-1984, and Hainan Island (China) in 1985 $(5.2-19.4 \%)(38-40,47)$.

The liver enzyme elevations seen in patients in Puerto Rico were very similar to those described in patients with DF in Taiwan in 1987-1988, and in hospitalized patients with a clinical diagnosis of dengue in Puerto Rico in 1991 (48, 49). Other recent reports have underscored the relationship of dengue infection, liver involvement, and encephalopathy (50-52). The three patients with DHF/DSS grade IV (of whom two died) had the highest AST levels found among the 57 cases of DHF described here.
As was to have been expected, all 57 patients received intravenous fluid therapy, while only two $(3.5 \%)$ received plasma. The administration of platelets, steroids, and intravenous immune globulin was motivated by marked thrombocytopenia. (The patient's condition usually requires that the physician decide on therapy before receiving the results of testing for dengue or any other etiology-53.)

As shown by other analyses of the role of immune response in case severity, we were able to document that in most confirmed cases the patient's immunologic response to the virus indicated a secondary infection (54). The age distribution for DHF in Puerto Rico (and other countries in the Americas) seems markedly different from that found in Southeast Asia, where the population has been exposed to endemic dengue and frequent epidemics for several decades $(41,42,55$, 56). In Indonesia, for example, the median age for patients with DHF from 1979 through 1984 was 4 years 11 months (57). In contrast, the median age in Puerto Rico was 38 years (with a range of 4 to 86 years). Although infant deaths due to dengue have been documented in Puerto Rico in other years, no infant deaths attributable to dengue occurred during the two years of this study (44).

Most DHF case descriptions typically come from patients evaluated at one hospital or dengue research center in areas where the dengue incidence is high. In contrast, this description is based on a combination of passive and active surveillance systems established for the guidance of disease control efforts in Puerto Rico (20). In general, dengue diagnosis depends upon collection of repeated, properly timed, and promptly processed serum samples. These conditions are seldom met in routine clinical care, and cannot be met when the patient dies after a short illness.

As suggested by comparison of the mean intervals from disease onset to hospital discharge among three groups of our study subjects (see Table 2), the shortness of the period available for clinical observation is an important ob- 
stacle to dengue diagnosis and reporting. This helps to explain the low proportion of laboratory-confirmed cases $(15 / 57=26 \%)$ among DHF patients for whom laboratory diagnosis was performed, as well as the high proportion of indeterminates $(29 / 102=28 \%)$ among clinically diagnosed cases of DHF. Inaccuracies in reporting the date of onset of symptoms may also produce misdiagnosis, because cases will be misclassified as laboratorynegative instead of indeterminate if the interval between actual disease onset and blood collection is too short for a diagnostic antibody rise.

The etiology of the illnesses that fulfilled the clinical criteria for DHF but did not yield positive laboratory results for dengue cannot be defined by the data available to this study. It seems reasonable to think that a large propor- tion of the indeterminate cases were dengue, while the rest, together with the negative cases, might have been due to infectious diseases capable of producing dengue-like symptoms (diseases such as leptospirosis, measles, influenza, and many others) or the coincidence of an acute febrile episode with noninfectious conditions (such as leukemia).

In summary, the clinical characteristics of 1990-1991 laboratory-positive cases of DHF in Puerto Rico were similar to the characteristics of DHF cases described in other countries, while the age-distribution of cases followed the pattern found in the Americas (with all age groups being affected) as opposed to that found in Southeast Asia (where the disease occurs predominantly in younger children). The number of DHF cases identified by means of this study was 2.85 times higher than that reported, and the actual number of cases that occurred appears likely to have been higher still. Recognition of DHF and its reporting by clinicians needs to be improved.

Acknowledgments. The authors wish to recognize the foresight of Edward B. Hayes, M.D., and Duane J. Gubler, Sc.D., who established the hospital surveillance system for severe dengue on which this investigation was based. The collaboration of the laboratory staff at the Dengue Branch, U.S. Centers for Disease Control and Prevention, was crucial for identification of the cases summarized in this study and is hereby gratefully acknowledged.

\section{REFERENCES}

1. Institute of Medicine. Emerging infections: microbial threats to health in the United States. Washington, DC: National Academy Press; 1992.

2. Centers for Disease Control and Prevention. Addressing emerging infectious disease threats: a prevention strategy for the United States. Atlanta: U.S. Department of Health and Human Services, Public Health Service; 1994.

3. Halstead SB. The XXth century dengue pandemic: need for surveillance and research. World Health Stat Q 1992;45:292-298.

4. Nimmannitya S. Clinical spectrum and management of dengue haemorrhagic fever. Southeast Asian J Trop Med Public Health 1987; 18:392-397.

5. Sumarmo, Wuryadi S, Gubler DJ. Clinical observations on hospitalized patients with virologically confirmed dengue hemorrhagic fever in Jakarta, Indonesia 1975-1983. Paediatr Indones 1986;26:137-151.

6. Chin CK. Outpatient management of dengue infection in the University Hospital, Kuala Lumpur. Malays J Pathol 1993;15:21-23.

7. Rohde JE. Clinical management of severe dengue. Trop Doct 1978;8:54-61.

8. Tassniyom S, Vasanawathana V, Chirawatkul A, Rojanasuphot S. Failure of high-dose methylprednisolone in established dengue shock syndrome: a placebo-controlled, double-blind study. Pediatrics 1993;92:111-115.

9. Lum LCS. Management of dengue haemorrhagic fever/dengue shock syndrome. Malays I Pathol 1993;15:29-33.

10. Yong BH. Critical care aspects of dengue haemorrhagic fever/dengue shock syndrome. Malays J Pathol 1993;15:35-39.
11. Sumarmo, Wulur H, Jahja E, Gubler DJ, Suharyono W, Sorensen K. Clinical observations on virologically confirmed fatal dengue infections in Jakarta, Indonesia. Bull World Health Organ 1983;61:693-701.

12. López Correa RH, Cline BL, Ramírez-Ronda C, Bermúdez R, Sather GE, Kuno G. Dengue fever with hemorrhagic manifestations: a report of three cases from Puerto Rico. Am J Trop Med Hyg 1978;27:1216-1224.

13. Woodall JP, López-Correa RH, Sather GE, Moore CG. The absence of epidemic dengue hemorrhagic fever from the Americas. In: Hotta S, ed. Dengue hemorrhagic fever 1981: proceedings of the First International Center for Medical Research Seminar 1980, Nov 21-22, Kobe, Japan. Kobe: ICMR; 95-106.

14. Álvarez ME, Ramírez-Ronda $\mathrm{CH}$. Dengue and hepatic failure. Am J Med 1985;79:670-674.

15. Gubler DJ. Dengue and dengue hemorrhagic fever in the Americas. P R Health Sci J 1987; 6:107-111.

16. Ramírez-Ronda $\mathrm{CH}$. Dengue in Puerto Rico: clinical manifestations and management from the 1960s to 1987. P R Health Sci J 1987;6: 113-118.

17. Pan American Health Organization. Dengue in the Americas: an update. Epidemiol Bull (PAHO) 1993;14:1-3.

18. Rigau-Pérez JG, Gubler DJ, Vorndam AV, Clark GG. Dengue surveillance: United States, 1986-1992. In: Centers for Disease Control and Prevention. CDC surveillance summaries. 22 July 1994;43(No. SS-2):7-19.

19. World Health Organization. Dengue haemorrhagic fever: diagnosis, treatment, and control. Geneva: WHO; 1986:12-14.
20. Gubler DJ. Surveillance for dengue and dengue hemorrhagic fever. Bull Pan Am Health Organ 1989;23:397-404.

21. Gubler DJ, Casta-Vélez A. A program for prevention and control of epidemic dengue and dengue hemorrhagic fever in Puerto Rico and the U.S. Virgin Islands. Bull Pan Am Health Organ 1991;25:237-247.

22. Jordan CD, Flood JG, Laposata M, Lewandrowski KB. Normal reference laboratory values. N Engl J Med 1993;327:718-724.

23. Anonymous. JAMA instructions for authors. JAMA 1995;273:27-34.

24. Yager HM, Harrington JT. Urinalysis and urinary electrolytes. In: Jacobson HR, Striker $\mathrm{GE}, \mathrm{Klahr} \mathrm{S}$, eds. The principles and practice of nephrology. Philadelphia: Decker; 1991:171.

25. Rosen L, Gubler DJ. The use of mosquitoes to detect and propagate dengue viruses. Am J Trop Med Hyg 1974;23:1153-1160.

26. Gubler DJ, Kuno G, Sather GE, Vélez M, Oliver A. Mosquito cell cultures and specific monoclonal antibodies in surveillance for dengue viruses. Am J Trop Med Hyg 1984;33: 158-165.

27. Kuno G, Gubler DJ, Vélez M, Oliver A. Comparative sensitivity of three mosquito cell lines for isolation of dengue viruses. Bull World Health Organ 1985;63:279-286.

28. Burke DS, Nisalak A, Ussery MA. Antibody capture immunoassay detection of Japanese encephalitis virus immunoglobulin M and G antibodies in cerebrospinal fluid. J Clin Microbiol 1982;15:1034-1042.

29. Gubler DJ, Sather GE. Laboratory diagnosis of dengue and dengue hemorrhagic fever. In: 
Fonseca da Cunha F, ed. Simposio Internacional sobre Febre Amarela e Dengue, 1988. Rio de Janeiro: Fundação Oswaldo Cruz/BioManguinhos; 1990:291-322.

30. Kuno G, Gómez I, Gubler DJ. Detecting artificial anti-dengue $\operatorname{IgM}$ immune complexes using an enzyme-linked immunosorbent assay. Am J Trop Med Hyg 1987;36:153-159.

31. Chungue E, Marché G, Plichart R, Boutin JP, Roux J. Comparison of immunoglobulin $\mathrm{G}$ enzyme-linked immunosorbent assay (IgGELISA) and haemagglutination inhibition (HI) test for the detection of dengue antibodies: prevalence of dengue IgG-ELISA antibodies in Tahiti. Trans $R$ Soc Trop Med Hyg 1989;83:708-711.

32. Clarke DH, Casals J. Techniques for hemagglutination and hemagglutination-inhibition with arthropod-borne viruses. Am J Trop Med Hyg 1958;7:561-573.

33. Hall WC, Crowell TP, Watts DM, Barros VL, Kruger H, Pinheiro F, et al. Demonstration of yellow fever and dengue antigens in formalin-fixed paraffin-embedded human liver by immunohistochemical analysis. Am J Trop Med Hyg 1991;45:408-417.

34. Gubler DJ, Suharyono W, Lubis I, Eram S, Sulianti Saroso J. Epidemic dengue haemorrhagic fever in rural Indonesia: I. virological and epidemiological studies. Am J Trop Med Hyg 1979;28:701-710.

35. Centers for Disease Control. Case definitions for public health surveillance. MMWR 1990; 39:RR-13, 10-11.

36. Lewis JG, Chang G-J, Lanciotti RS, Kinney RK, Mayer LW, Trent DW. Phylogenetic relationships of dengue-2 viruses. Virology 1993; 197:216-224.

37. Nimmannitya S, Halstead SB, Cohen SN, Margiotta MR. Dengue and chikungunya virus infection in man in Thailand, 1962-64: I. observations on hospitalized patients with hemorrhagic fever. Am J Trop Med Hyg 1969; 18:954-971.
38. Hayes CG, Manaloto CR, Gonzales A, Ranoa CP. Dengue infections in the Philippines: clinical and virological findings in 517 hospitalized patients. Am J Trop Med Hyg 1988;39: 110-116.

39. Qiu F-X, Gubler DJ, Liu J-C, Chen Q-Q. Dengue in China: a clinical review. Bull World Health Organ 1993;71:349-359.

40. Guzmán MG, Kourí GP, Bravo J, et al. Dengue haemorrhagic fever in Cuba: II. clinical investigations. Trans R Soc Trop Med Hyg 1984;78: 239-241.

41. Rosso F, Restrepo de Meza MT, Alzate A, Muñoz J, Moreno $\mathrm{CH}$. Dengue hemorrágico en el Hospital Universitario del Valle, 19901992. Colombia Med 1994;25:10-14.

42. Zagne SMO, Alves VGF, Nogueira RMR, Miagostovich MP, Lampe E, Tavares W. Dengue haemorrhagic fever in the state of Rio de Janeiro, Brazil: a study of 56 confirmed cases. Trans R Soc Trop Med Hyg 1994;88:677-679.

43. Moreau J-P, Rosen L, Saugrain J, Lagraulet J. An epidemic of dengue on Tahiti associated with hemorrhagic manifestations. Am J Trop Med Hyg 1973;22:237-241.

44. Dietz VJ, Gubler DJ, Ortiz S, et al. The 1986 dengue and dengue hemorrhagic fever outbreak in Puerto Rico: epidemiologic and clinical observations. P R Health Sci J 1996;15: 201-210.

45. Munir M, Husada T, Mustadjab I. Dengue haemorrhagic fever: a problem of clinical diagnosis and proposal for using a scoring system. Paediatr Indones 1982;22:11-22.

46. Srivastava VK, Suri S, Bhasin A, Srivastava L, Bharadwaj M. An epidemic of dengue haemorrhagic fever and dengue shock syndrome in Delhi: a clinical study. Ann Trop Paediatr 1990;10:329-334.

47. Eram S, Setyabudi Y, Sadono TI, Sutrisno DS, Gubler DJ, Sulianti Saroso J. Epidemic dengue hemorrhagic fever in rural Indonesia: II. clinical studies. Am J Trop Med Hyg 1979;28: 711-716.
48. Kuo CH, Tai DI, Chang-Chien CS, Lan CK, Chiou SS, Liaw YF. Liver biochemical tests and dengue fever. Am J Trop Med Hyg 1992; 47:265-270.

49. García S, Morales R, Hunter RF. Dengue fever with thrombocytopenia: studies towards defining vulnerability of bleeding. Bol Asoc Med P R 1995;87:2-7.

50. Innis BL, Myint KSA, Nisalak A, Ishak KG, Nimmannitya S, Laohapand T, et al. Acute liver failure is one important cause of fatal dengue infection. Southeast Asian J Trop Med Public Health 1990;21:695-696.

51. Lum LCS, Lam SK, George R, Devi S. Fulminant hepatitis in dengue infection. Southeast Asian J Trop Med Public Health 1993;24: 467-471.

52. Rajajee S, Mukundan D. Neurological manifestations in dengue hemorrhagic fever. Indian Pediatr 1994;31:688-690.

53. College of American Pathologists. Practice parameter for the use of fresh-frozen plasma, cryoprecipitate, and platelets. JAMA 1994;271: 777-781.

54. Halstead SB. Pathogenesis of dengue: challenges to molecular biology. Science 1988;239: 476-481.

55. Kourí GP, Guzmán MG, Bravo JR, Triana $C$. Dengue haemorrhagic fever/dengue shock syndrome: lessons from the Cuban epidemic, 1981. Bull World Health Organ 1989;87:375-380.

56. Communicable Diseases Program, PAHO Dengue hemorrhagic fever in Venezuela. Epidemiol Bull (PAHO) 1990;11(2):7-9.

57. Nathin MA, Harun SR, Sumarmo. Dengue haemorrhagic fever and Japanese B encephalitis in Indonesia. Southeast Asian J Trop Med Public Health 1988;19:475-481.

Manuscript received on 10 April 1996. Revised version accepted for publication on 21 August 1996.

RESUMEN Este estudio se realizó con el fin de mostrar que la fiebre hemorrágica dengue (FHD) se da en Puerto Rico, si bien es una enfermedad subnotificada, lo que se debe en parte a su subdiagnóstico en los hospitales. La vigilancia de casos graves de dengue permitió determinar que hubo 986 hospitalizaciones por sospecha de dengue en el período de 1990-1991. En esa época, el sistema de vigilancia identificó 20 casos de FHD, incluidos tres de síndrome de choque por dengue (SCD). Nuestra revisión subsecuente de los expedientes de los 986 pacientes reveló que en 102 de ellos había razones para apoyar el diagnóstico clínico de FDH (88) y de SCD (14). Entre estos 102 había 57 que dieron resultados virológicos o serológicos positivos a dengue y reunían los criterios de caso de dengue establecidos por la Organización Mundial de la Salud (fiebre, manifestaciones hemorrágicas, trombocitopenia y excesiva permeabilidad capilar). En el grupo de 57 pacientes, la media de edad era de 38 años y preponderaban los hombres (34, o sea $59,3 \%$ ), incluidos ocho casos de SCD y dos (3,5\%) defunciones (en mujeres de 16 y 55 años de edad). Los síntomas hemorrágicos fueron leves y con frecuencia se observaron hemoconcentración, hipoalbuminemia y concentraciones elevadas de aspartato y alanina aminotransferasas. Las hospitalizaciones duraron unos 5 días en término medio. La descripción clínica de estos casos de FHD en Puerto Rico coincide con descripciones anteriores de la enfermedad en la literatura médica, pero la distribución por edad de los pacientes es similar al patrón que se suele encontrar en las Américas (donde afecta a todos los grupos de edad), en contraste con el de Asia sudoriental (donde afecta principalmente a niños pequeños). El número de casos identificados en nuestro estudio fue casi tres veces mayor que el número notificado por el sistema de vigilancia establecido. Nuestros resultados indican que es necesario mejorar la capacidad de los clínicos locales para reconocer y notificar los casos de FHD. 